Maria do Rosário Dias ${ }^{1}$

Recebido: 30-04-2018

Kateryna Rudysh ${ }^{2}$

Letícia Naben $^{3}$

Ana Lúcia Monteiro ${ }^{4}$

Aprovado: 18-05-2018 / Publicado: 13-06-2018

DOI: https://doi.org/10.23882/OM08-2-2018-B

\title{
O ESPREITAR DO MORRER A pintura do pensamento da morte
}

Resumo: O presente artigo pretende relevar as primordiais características associadas à vivência da morte, do luto e da perda ao longo do ciclo vital. A idade, a cultura e a vivência pessoal de cada indivíduo influenciam a visão de Ser Humano. As crianças, psicologicamente ainda imaturas, incapazes de interiorizar o conceito de morte e as suas implicações não têm, por vezes, capacidade de realizar o processo de luto na sua plenitude. Os adolescentes, vítimas de um otimismo irrealista, característico desta fase, desafiam a morte através de comportamentos de risco colocando a vida em redomas de perigosidade. Na Adultícia, a morte é compreendida em plenitude sendo caraterizada pela tristeza, frustração e ira. Por outro lado, os idosos são aqueles que parecem ter uma maior consciência da efemeridade da vida e quando enlutados tendem a fazer uma introspeção da vida e a refugiar-se na sua família.

Palavras-chave: Morrer, desenvolvimento do ciclo vital, morte, luto, perda.

\section{A PEEK AT DYING A painting of the thought of death}

\begin{abstract}
The present article intends to highlight the primordial characteristics associated to the experience of death, mourning and loss throughout the life cycle. The age, culture and personal experience of each individual influences the vision of Being $\mathrm{Hu}-$ man. Children, psychologically still immature, unable to internalize the concept of death and its implications do not sometimes have the capacity to perform the grieving process in its fullness. Adolescents, victims of an unrealistic optimism, characteristic of this phase, defy death through risky behaviors, putting life in danger. In Adultery, death is fully understood and characterized by sadness, frustration, and anger. On the other hand, the elderly seems to have a greater awareness of the ephemerality of life and when mourners tend to make an introspection of life and take refuge in their family.
\end{abstract}

Keywords: Dying, development of the life cycle, death, mourning, loss.

\footnotetext{
${ }^{1}$ Professora Associada do Instituto Universitário Egas Moniz (Portugal)

Doutorada em Psicologia Clínica pela Universidade de Lisboa (mariadorosario.dias@gmail.com)

${ }^{2}$ Investigadora auxiliar do EM-CIMPS - Centro de Investigação Interdisciplinar Egas Moniz (Portugal) Mestranda do Mestrado Integrado em Medicina Dentária do Instituto Universitário Egas Moniz (katerynarudysh@gmail.com)

${ }^{3}$ Investigadora auxiliar do EM-CIMPS - Centro de Investigação Interdisciplinar Egas Moniz (Portugal) Licenciada em Ciências da Saúde pelo Instituto Universitário Egas Moniz (le_garcia97@live.com.pt)

${ }^{4}$ Investigadora auxiliar do EM-CIMPS - Centro de Investigação Interdisciplinar Egas Moniz (Portugal) Aluna da Licenciatura em Ciências da Saúde pelo Instituto Universitário Egas Moniz (ana.lucia.1998@ @apo.pt)

* O texto das autoras não segue o Novo Acordo Ortográfico para a Língua Portuguesa
} 


\section{Introdução}

Em 1916, Klimt pinta o quadro intitulado "Morte e Vi$d a "$ (Fig.1). Do lado esquerdo do quadro, fazendo uso de cores frias e sombrias, a morte é simbolicamente representada como um esqueleto, que usa uma túnica azul cravada de cruzes pretas de diversas formas e tamanhos, ao mesmo tempo que, segura um ceptro vermelho que simboliza o poder da morte sobre a vida e adota uma posição imponente semelhante à de um predador que espera pela fragilidade da sua presa. Do lado direito, com auxílio de cores quentes e exuberantes, a vida é ilustrada através de um aglomerado de figuras humanas sobrepostas e inertes parecendo representar um ninho de Seres Humanos em vários estádios do ciclo vital. De uma maneira geral, todos os figurantes se encontram a dormir pacificamente como se a morte não existisse. A excepção pictórica é assumida pelo indivíduo mais velho ao

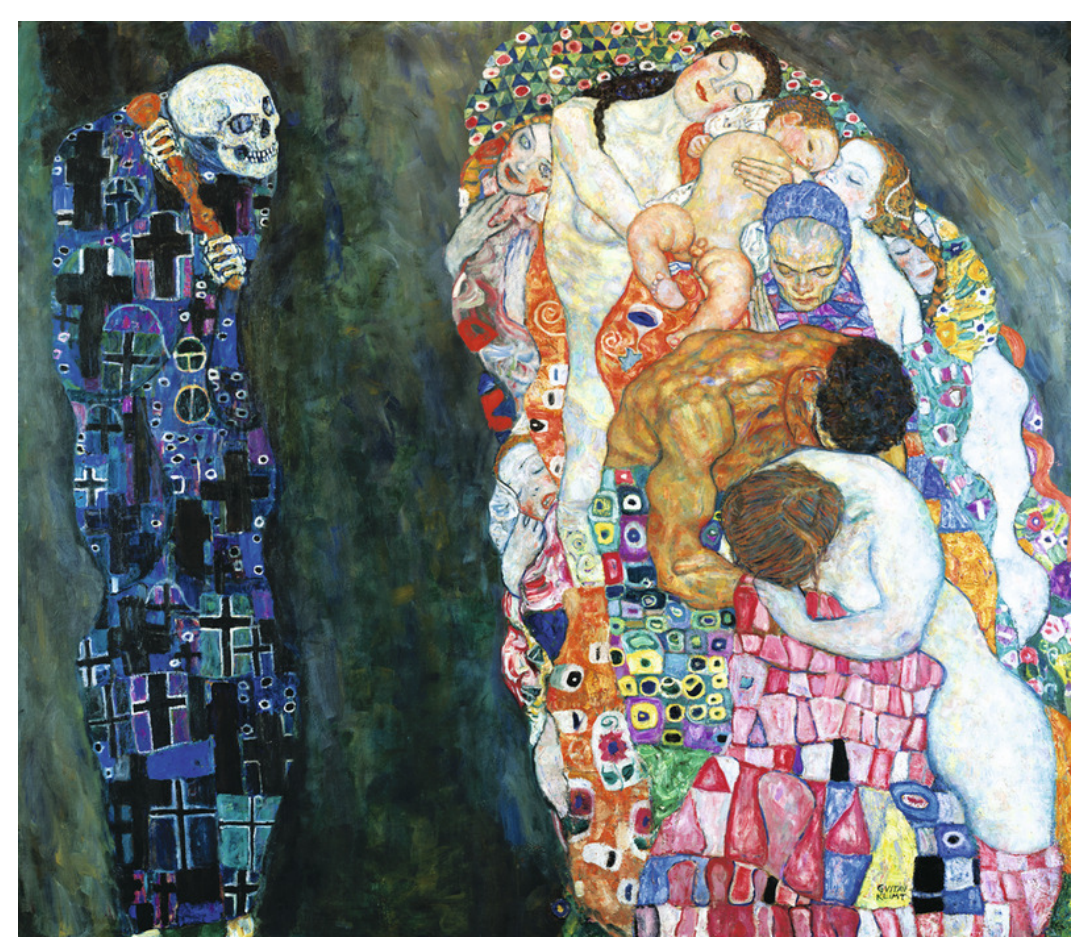

Figura 1 - Gustav Klimt, Morte e Vida, 1910/15 @ Museu Leopold, Viena
Também Kübler-Ross (1996) parece ir ao encontro desta abordagem intrínseca do imaginário do pintor, ao defender a morte como um processo integral da vida, tão natural e previsível como o nascimento do Humano. Mas, enquanto o nascimento é detonado pelo triunfo da celebração, a morte continua a ser vivenciada como um tema tabu, a ser negada e soterrada pela mente dos seres vivos.

\section{1. (Re)pensar sobre a morte e o morrer}

$\mathrm{Na}$ correspondência entre Heidegger e Jaspers (Arendlt, 1992), em 1926, estes dois filósofos definiram a condição de Morte como sendo a condição que nos permite viver a vida de maneira autêntica. Já na perspetiva de Santos (1997), a morte é um estado da vida e não o seu último momento, morremos desde o nascimento, 0 final está cadentemente presente desde a génese Huma$n a$. Neste sentido, a morte deve ser encarada como um fenómeno natural, uma vez que 0 organismo só se mantém vivo à custa da morte de milhões de células que se renovam constantemente, num genuíno processo vital em incessante equilíbrio.

Devemos, então, encarar a morte como um processo que faz parte do desenvolvimento humano e está presente no nosso quotidiano de vida (Combinato e Queirós, 2006). Contudo, Freud (1925) ajuda-nos compreender a repulsa vivida face à morte, na vertente clínica, ao afirmar que o inconsciente não parece deter nenhuma representação mental do que será morrer ou deixar de existir. Ao analisar as sociedades, Freud constata que um dos maiores medos do Homem é ver o seu próprio corpo definhar podendo este

centro, que se destaca dos restantes, pela sua atitude discernida perante a presença da morte - a posição cabisbaixa, o rosto triste e 0 ato de rezar denunciam a sua consciência do espreitar da morte e da efemeridade da vida. facto, trazer-lhe insatisfação e sofrimento. Nesta linha de registo, Huizinga (2010) descreve a morte como algo metaforicamente clandestino, em que sobrevive o fingimento do sentir, de tal forma que, todos os seus sinais estão camuflados pelas pegadas da vida. 


\subsection{Sobre as tipologias da Morte}

Podemos considerar que o Ser Humano pode vivenciar mais do que uma morte na verdadeira acepção da palavra. A morte biológica diz respeito ao fim de todos os processos biológicos e a perda irreversível de toda a unidade biológica (Santos, 1997). A morte clínica ocorre quando o organismo deixa de funcionar como uma unidade auto-suficiente, apesar de os pulmões e o coração poderem funcionar através de um suporte artificial, embora privados de algumas funções antes consideradas vitais. Este facto, leva Portugal, numa declaração da Ordem dos Médicos (artigo $12^{\circ}$ da Lei ${ }^{\circ} 12 / 93$, de 22 de Abril), a adotar como critério de morte clínica - a morte do tronco cerebral. Para tal, são efetuados testes em que o paciente para ser considerado morto, tem de se verificar, a ausência irreversível de batimentos cardíacos e de respiração, bem como, ausência total de resposta nos testes cerebrais (Lima, 2004).

A morte psicológica diz respeito aos sentimentos que alguém experiencia quando sabe que ela própria ou alguém de quem gosta vai morrer. Barbosa, Melchiori e Nene (2011) descrevem este tipo de morte como alguém que se vê reduzido às suas possibilidades de existência, negando-se a viver, pois não vê razões para a plenitude da Vida. $\mathrm{O}$ último tipo de morte diz respeito à morte sociológica e pode ser definido como a perda de identidade social (Králová, 2015), como resultado da quebra de relações pessoais e humanas de forma permanente, devido ao abandono e afastamento pessoal das suas relações com o Outro.

\subsection{A pré-concepção da morte ao longo do ciclo vital}

A forma como encaramos a morte depende da personalidade, da educação e da vivência pessoal de cada um no decurso da trajetória de vida (Papalia, Olds e Felman, 2000). A consciencialização da finitude tende a exaltar no Ser Humano uma angústia de perda exacerbada que torna a aceitação da morte um processo extremamente doloroso (Bousso, Ramos, Frizzo, Santos e Bousso, 2014). Segundo Freud (1925), a morte é inconcebível e inimaginável, no fundo, pois ninguém acredita na sua própria morte. Assim sendo, a morte não assume uma existência para o inconsciente, conduzindo-se na vivên- cia intrapsíquica, como se fosse imortal.

A morte para as crianças na idade pré-escolar é percepcionada como reversível (Torres, 1999) pelo que consideram que os mortos se comportam como vivos (Barros de Oliveira, 1998).

Contudo, na idade escolar, entre os cinco e os nove anos de idade, assiste-se a um grande crescimento intrapsíquico ao nível da perceção da morte (Torres, 1999). Neste estádio, a criança já consegue interiorizar três critérios intrínsecos à morte: a sua irreversibilidade, permanência e a sua universalidade (Black, 1998). É também importante salientar que segundo Parkes (2009), os Educadores Psicossociais parecem ter alguma dificuldade na abordagem desta temática, mesmo quando um acontecimento de morte invade o espaço escolar. Com o objectivo de perceber em que faixas etárias as crianças conseguem ter a noção dos três fatores que caracterizam a morte foi realizado por Feifel, um estudo no século passado sobre esta problemática, nomeadamente em 1977. As crianças tinham idades compreendidas entre os quatro e os nove anos, e foram confrontadas com a seguinte situação: "Duas crianças vão com frequência a uma confeitaria que pertence a uma senhora idosa. Um dia a senhora morre". De seguida, perguntou-se às crianças o porquê de a senhora ter morrido e o que representava a morte para cada uma delas. As respostas obtidas envolveram uma panóplia de concepções. As crianças de quatro anos afirmaram, na sua maioria, que a senhora iria voltar a acordar, facto esse que corroborava a sua incapacidade de perceber que a morte assume um caracter permanente. Na generalidade, as crianças de sete anos compreenderam que o coração da senhora parou e que esta não podia voltar a viver, contudo, mantinham a ideia no seu imaginário que as crianças vivem eternamente, não tendo ainda, a perceção de que a morte tem um carácter etário universal. Por fim, as crianças de nove anos pareciam ter perfeita consciência da universalidade e da permanência da morte, afirmando que a senhora da história narrada "foi para um lugar melhor". (Lamers Jr., 2012)

A maioria dos adolescentes vivencia sentimentos ambivalentes face ao conceito de morte. Porém, alguns adolescentes atribuem-lhe conotações algo extraordiná- 
rias e misteriosas e por outro lado, preferem condensar o seu pensar no presente do que exacerbar o futuro (Offer, Ostrov, Howard e Atkinson, 1988). Na verdade, registase um otimismo irrealista típico deste estádio de vida acreditando os sujeitos que são invulneráveis, mesmo quando correm riscos imprudentes (Elkind, 1984; Feifel, 1977; Offer, Ostrov, Howard e Atkinson, 1988).

Os adultos têm a consciência plena da morte, uma vez que compreendem todos os aspetos que a caracterizam. Tal, advém do facto, do seu corpo dar sinais de que já não são tão jovens como outrora, ágeis e vigorosos (Papalia, Olds e Felman, 2000) e também pelo facto, de a morte do Outro se começar a tornar recorrente na sua vida. Por volta dos 40 a 50 anos, muitas funções físicas alteram-se e diminuem e os sinais de envelhecimento manifestam-se de modo mais evidente (Carter e McGoldrick, 2001). Consequentemente, apercebem-se de que a morte deixa de ser tão distante e que a finitude da vida é inevitável, o que os leva a fazer permanentes balanços das suas vidas (Kovács, 1992) e a ter uma grande ansiedade de viver a vida (Bee, 1997).

Os adultos têm também noção do significado social da morte parecendo reflectir-se na mudança de papéis e relações interpessoais de cada um na família. Segundo Scharlach e Fredriksen (1993), quando morrem ambos os pais de um adulto, o sujeito tem uma consciência emergente de vir a fazer parte da próxima geração de idosos na fila para morrer; quando morre uma pessoa de meiaidade "a tejetória de gerações" fica fragmentada e deixa de haver alguém na geração sandwich a prestar cuidados aos mais novos e aos mais velhos. Quando morre um filho adulto, adolescente ou criança, os pais perdem, também, parte do seu papel de transgeracional.

A terceira idade é o "terceiro mundo da vida". Diz respeito a uma experiência inédita para cada indivíduo, com dimensões simbólicas, sociais e culturais dependentes de cada um (Pereira, Giacomin, e Firmo, 2015). Segundo Le Breton (2011), o problema da velhice é estar sempre acompanhada da ideia da morte e da precariedade da condição Humana. A velhice representa, então, o instante em que o corpo se deixa de mostrar favorável ao olhar do Outro. Assim, numa perspetiva dialética, a experiência corporal do envelhecimento acaba por se transformar numa experiência social, reforçada pela degeneração orgânica irreversível, com declínio das funções e das reservas fisiológicas, levando o indivíduo, consequentemente, à morte.

Para os idosos, a morte é acompanhada por uma crise relacionada com o final da integridade versus desespero, pois sentem que a morte está próxima. Segundo Erikson (1998), os idosos que resolvem esta crise conquistam a aceitação intrapsíquica do que fizeram com as suas vidas como da morte iminente.

$\mathrm{O}$ ditado latino senectus ipsa morbus est refere que a velhice é, ela própria, uma doença crónica. Esta visão milenar da velhice como uma tragédia pessoal inexorável, irreversível e irremediável está, ainda, presente no imaginário da velhice na cultura ocidental (Pereira, Giacomin e Firmo, 2015).

Yount (2009) abordou o conceito de gerotranscendência e afirmou que, quem encara a finitude da vida com serenidade e sabedoria, experiência um envolvimento vital. Este conceito remete para o acolhimento da morte e a sua não negação, de modo a que, aproveitemos a vida da melhor maneira possível. As pessoas que são capazes de entender que as suas vidas tiveram um significado singular, assumem ser mais capazes de enfrentar a morte. Por fim, o idoso abriga ressentimentos acerca da brevidade da vida e o facto de não poder, irremediavelmente, começar tudo de novo.

\subsection{Sobre a trajetória da Morte e as "sombras" do luto}

Como defende Barbosa, Melchiori e Nene (2011) todos vamos morrer um dia, embora a maioria das pessoas desconheça o momento exato em que tal vai acontecer. A menos que a morte chegue de repente, devido a um acidente ou ataque cardíaco, as pessoas seguem uma trajetória da morte que diz respeito ao intervalo de tempo que necessitam para perceber que, a morte é iminente, para se adaptarem ao significado que ela tem e ao real momento da morte (Glaser e Strauss, 1965; Barbosa, Melchiori e Nene 2011).

Kübler-Ross, psiquiatra suíça, tratou e acompanhou pacientes em estado terminal e através de longas conver- 
sas com mais de duzentos doentes, conseguiu identificar cinco estádios de vivência psíquica percorridos pelo indivíduo quando sabe que vai morrer. Muitas destas entrevistas/conversas estão fidedignamente relatadas no seu livro "Sobre a morte e o morrer" (1969) que empiricamente revolucionou a comunidade científica na época, ao abordar de forma realista a maneira como os médicos lidam com os doentes, mas também os seus familiares. Nesta linha de registo, há cinco estágios da morte segundo a perspectiva empírica de Kübler-Ross (1996). O primeiro designa-se por dialéctica da negação, durante a qual a pessoa nega aceitar a morte e pode mesmo entrar em estado de choque. Embora esta etapa possa ser ultrapassada, pode haver um retrocesso em que a pessoa volta a negar o seu destino. No caso da negação se tornar persistente, o sujeito pode mesmo desencadear sentimentos de depressão e isolamento.

A segunda etapa é a da expressão colérica, em que a pessoa se expressa com raiva e cólera, estando sempre presentes os sentimentos de inveja e ressentimento. Kübler-Ross afirma ainda que, neste estádio, se deve deixar o sujeito exprimir a sua opinião e sentimentos, tentando, deste modo, aliviar a sensação de desconforto físico e emocional.

O terceiro estágio é o da dialética da reciprocidade negociável, sendo esta emoção vivenciada como uma forma de defesa maciça no decurso da qual, o paciente tenta desesperadamente ingressar em estratégias de negociação com os Médicos, as Enfermeiras, os familiares e inevitavelmente - Deus. Os pedidos de adiamento da morte sucedem-se, ao nível das promessas do indivíduo - em nunca mais voltar a pedir nada se lhe for concedido o pedido.

$\mathrm{Na}$ quarta etapa predomina a depressão, da qual emerge a desistência, a dialéctica e a constatação do agravamento do estado físico do sujeito, levando muitas pessoas a mergulhar no desespero durante longos períodos de tempo. Contudo, a depressão ou o desespero constituem -se como uma preparação necessária para a etapa final que se adivinha - a aceitação. Este processo envolve a perda socio-profissional, a perda financeira, a necessidade de sacrificar economicamente a família e posteriormente, surge inevitavelmente o sentimento de culpa, as- sistindo-se ao abandono das atividades de lazer apreciadas, intensa expressão disfórica, angústia profunda e o desinteresse geral. Como última etapa considera-se, a dialética da aceitação onde predomina a desistência na luta pela sobrevivência e uma aceitação passiva do fim. Frequentemente, os familiares recusam esta aceitação e insistem, muitas vezes, que o doente continue a lutar.

Sobre esta paradigmática teoria é possível tecer algumas recensões, pois as pessoas podem atravessar só algumas das etapas e, em diferentes momentos, Segundo a autora, sobrevivem, naturalmente as diferenças individuais emergentes. Nesta linha de registo, o género do paciente, a sua cultura, a personalidade, o nível de desenvolvimento e o lugar, condicionam a natureza das doenças terminais e faz com que cada morte seja idiossincraticamente, distinta.

Segundo Freud (1925) o luto é, em geral, uma reação à perda de uma pessoa amada, ou à perda de abstrações colocadas no seu lugar, tais como a pátria, a liberdade, entre outros. $\mathrm{O}$ luto configurase como um processo doloroso que não deve ser interrompido. Não pode ser consignado como uma patologia, pois assume-se como um processo natural na vida de todos os seres humanos, a menos que, essa reacção seja vivenciada como extremamente exagerada ou como causa de danos desmesurados à saúde física e mental dos sujeitos. O luto difere, assim, de indivíduo para indivíduo, mas em cada faixa etária relevam-se características comuns, pelo que o luto vivenciado nas diferentes faixas etárias é substancialmente díspar (Slate e Scott, 2009). Segundo Freud (1925) é através da marca da negação que o pensar se liberta das restrições da rejeição. $O$ luto assume-se, assim, como a experiência mais marcante e mais penosa vivenciada pelo ser humano, não havendo um tempo psíquico determinado para o final desse mesmo processo (Franco e Mazorra, 2007; Parkes, 2009). As concepções inovadoras de KüblerRoss, estendem-se a posteriori, a Bowlby (1980), Brown e Stoudemire (1983) e Sanders (1989), como suporte básico dos alicerces das teorias do luto.

Falar sobre a morte implica desencadear uma angústia latente face a esta condição, especialmente, quando se trata de conversar sobre esta temática com a criança. $\mathrm{O}$ silêncio do adulto sobre a morte, com o argumento de 
evitar sofrimento manifesto à criança, acaba por inibir a sua curiosidade e as manifestações afectivo-emocionais. Kovács (1992) argumenta ainda que, a criança apresenta uma aguda capacidade de observação e quando o adulto tenta evitar falar sobre o tema da morte com a criança, a sua reação pode ser amplificada, bem como a manifestação de sintomatologia associada. Neste sentido, Dias, Duque e Silva (2002) referem que a reação da familia nuclear é de importância fundamental, e o facto de a criança participar em rituais como velórios e enterros, em qualquer idade, ajuda substancialmente à elaboração de uma perda, oferecendo conforto psíquico à criança na expressão dos seus sentimentos (Alves \& Kovács, 2016). Na idade escolar, as principais alterações comportamentais refletem-se a nível do desempenho escolar, nomeadamente, a falta de concentração, interesse e motivação. Releva-se, assim, uma maior resistência em frequentar a escola, períodos de choro, nervosismo e comportamentos mitómanos frequentes.

Segundo estudos efetuados por Kóvacs e Rodriguez (2005) assim como por, Barbosa Melchiori e Neme (2011), os adolescentes apresentam uma capacidade cognitiva semelhante à do adulto. Contudo, é importante apoiar os adolescentes em todos os momentos do processo de luto quer resulte da perda de um membro da família ou de amigos (Groollman, 1993; Peruzzo, Jung, Soares e Scarparo, 2007). A participação dos pais, amigos e profissionais de saúde no processo de luto, tornase também fundamental para a superação da perda. $\mathrm{Na}$ verdade, os adultos experienciam o luto numa panóplia emocional altamente diferenciada uma vez que, se encontram encapsulados numa geração sandwich (trajetória familiar) que remete para a responsabilidade de cuidar dos mais novos e dos mais velhos.

Partindo do que diz Barbosa, Melchiori e Neme (2011), os idosos sofrem várias perdas ao longo a trajetoria de vida passando, assim, por diversos processos de luto. No entanto, é na velhice que num curto espaço de tempo, essas perdas se acentuam. A morte do cônjuge e de amigos próximos, mas também de um filho ou neto, desencadeia no idoso sentimentos de dor e tristeza que o levam a repensar a sua vida e a reorganizá-la ou, outras vezes, a desejar a sua própria morte.

\section{Conclusão}

Com a elaboração do presente artigo, pretendemos refletir sobre um leque de configurações associadas à morte, vivenciadas pelo Ser Humano, devendo o Homem encarar a morte como um processo intrínseco ao desenvolvimento do Humano. Procurámos igualmente desmitificar o tabu associado ao conceito de morte, reconvertendo-o, assim, para todos os estádios do ciclo vital.

Deste modo, suportados no percurso único da vida Humana, cada Pessoa tem um caráter único e distinto, manifestando-se em comportamentos e reacções próprias que refletem as experiências singulares de cada sujeito. De uma forma geral, de acordo com a perspetiva de vários autores consultados, ao longo da sua existência, os indivíduos atravessam cinco estádios de luto após a vivência de uma perda. Na verdade, o Ser Humano vacila (in)conscientemente que a sua existência é finita e que a maneira de lidar com a morte e a sua aceitação irá repercutir-se no processo de luto.

Ao longo do ciclo vital vai havendo cada vez mais uma maior consciencialização do que é a morte. Esta internalização da efemeridade da vivência da vida leva a que sentimentos de medo e de tristeza se tornem invasivos e persecurtórios.

As crianças devido à sua ténue maturação psicológica não são capazes de compreender a conceptualização da morte, encarando-a com mais naturalidade e frontalidade até aos 6 anos. 0 processo de elaboração da perda nesta faixa etária torna-se mais difícil, uma vez que, não têm total consciência do que a morte significa. Por outro lado, os adolescentes, ao entrarem na fase do otimismo irrealista consideram-se imunes à morte, acreditando na sua (in)vulnerabilidade e como tal, desafiam a vida ao vivenciarem experiências perigosas que os podem colocar em risco.

No decurso da adultícia, a morte é totalmente compreendida e pode ser encarada como um organizador de tempo mental, tomando o sujeito consciência de que a finitude da vida é inevitável. No entanto, tal não significa que não experienciem sentimentos mais negativos como a frustração e a raiva. Muitas vezes, por exemplo, a morte de um Ente querido pode levar à detonação de crises da Meia-Idade no Adulto. 
Os idosos são a geração que tem maior consciência da proximidade da morte e, por isso, tendem a recorrer à religião e à família como suporte Psicossocial. Ao terem uma maior noção do que é a morte, os idosos conseguem encará-la com maior naturalidade do que a maio- ria dos sujeitos de outros estádios, vivenciando uma percepção mais natural. No processo do luto, estes dois determinantes são também importantes, uma vez que é a experiência mais marcante e penosa do Ser Humano.

\section{Referências bibliográficas}

Alves, E.G.R.; Kovács, M. J. (2016). Morte de aluno: luto na escolar. Psicologia Escolar e Educacional, 20(2), 403406.

Arendt, H. (1992). Correspondence with Karl Jaspers 1926-1969. New York: Harcourt Brace.

Barbosa, C.G.; Melchiori, L.E.; Neme, C.M.B. (2011). O significado da morte para adolescentes, adultos e idosos. Paidéia, 21(49), 175-185.

Barros de Oliveira, J. (1998). Viver a morte. Abordagem antropológica e psicológica. Coimbra: Livraria Almedina.

Bee, H. (1997). O Ciclo Vital. Porto Alegre: Artmed.

Bousso, R.S.; Ramos, D.; Frizzo, H.C.F.; Santos, M.R.; Bousso, F. (2014). Facebook: um novo locus para a manifestação de uma perda significativa. Psicologia USP, 25(2), 172-179.

Bowlby, J. (1980). Attachment and loss: loss, sadness, and depression (Vol.3). New York: Basic Books.

Black, D. (1998). Bereavement in childhood. British Medical Journal, 316(7135), 931-933.

Brown, J.T.; Stoudemire, G.A. (1983). Normal and pathological grief. Journal of the American Medical Association, 250(3), 378-382.

Carter, B.; McGoldrick, M. (2001). As mudanças no ciclo de vida familiar - uma estrutura para a terapia familiar. In B. Carter and M. McGoldrick (Orgs.), As mudanças no ciclo de vida familiar: Uma estrutura de vida familiar. São Paulo: Artmed.

Combinato, D.S.; Queiroz, M.C. (2000). Morte: uma visão psicossocial. Estudos de Psicologia, 11(2), 209-216.

Dias, M.R.; Duque, A.; Silva, M. (2002). O lugar do silêncio e a perda psicossocial. Enfermagem Oncologica, 6(24), 11-29.

Elkind, D. (1984). All grown up and no place to go. Reading: Addison-Wesley.

Erikson, E.H. (1998). O ciclo de vida completo. Porto Alegre: Artes Médicas.

Feifel, H. (1977). New meanings of death. New York: McGraw-Hill.

Franco, M.H.P.; Mazorra, L. (2007). Criança e luto: vivências fantasmáticas diante da morte do genitor. Estudos de Psicologia, 24(4), 503-511. 
Freud, S. (1925). Obras Completas. Buenos Aires: Amorrortu

Glaser, B.G.; Strauss, A.L. (1968). Awareness of dying. Chicago: Aldine Publishing.

Grollman, E.A. (1993). Straight talk about death for teenagers: How to cope with losing someone you love. Boston: Beacon Press.

Huizinga, J. (2010). A imagem da Morte. O Outono da Idade Média. (pp.221-245. São Paulo: Cosac Naify.

Kóvacs, M.J.; Rodriguez, C. (2005). Falando de morte com o adolescente. Estudos e Pesquisas em Psicologia, 1, 127-143.

Kóvacs, M.J. (2002). Morte e desenvolvimento humano. São Paulo: Casa do Psicólogo.

Kübler-Ross, E. (1996). Sobre a morte e o morrer. São Paulo: Livraria Martins Fontes.

Králová, J. (2015). What is social death? Contemporary Social Science, 10(3), 235-248.

Lamers Jr., W.M. (2012). Herman Feifel, The meaning of death. Mortality, 17(1), 64-78.

Le Breton, D. (2011). Antropologia do corpo e modernidade (pp.2277-2279). Petrópolis: Editora Vozes.

Lima, C. (2004). Do conceito ao diagnóstico de morte: controvérsias e dilemas éticos. Medicina interna, 12(1), 6-10.

Offer, D.; Ostrov, E.; Howard, K.I.; Atkinson, R. (1988). The teenage world: Adolescents' self-image in ten countries. New York: Springer Science Business.

Papalia, D.E; Olds, S.W.; Felman, R.D. (2000). Desenvolvimento humano. Portalegre: Artmed.

Parkes, C.M. (2009). Amor e Perda: as raízes do luto e suas complicações. São Paulo: Summus Editorial. 